\title{
Turbulence Plus
}

\author{
Jerry Westerweel · Bendiks-Jan Boersma
}

Received: 6 April 2007 / Accepted: 11 May 2007 /

Published online: 23 August 2007

(C) Springer Science + Business Media B.V. 2007

\begin{abstract}
This paper attempts to give a concise overview of the turbulence research performed at the Laboratory for Aero and Hydrodynamics of the Delft University of Technology under the guidance of Frans Nieuwstadt. Frans Nieuwstadt was appointed in 1986 as director of the laboratory, and he held this position until his sudden death in 2005. Frans' principal interest was to investigate turbulence at a fundamental level, but also to consider turbulence and its role in other processes. He coined a name for this research: turbulence plus.
\end{abstract}

Keywords Turbulence P Pipe flow

\section{The Early Years}

Frans Nieuwstadt (Fig. 1) was appointed at the Chair of Fluid Mechanics of the Delft University of Technology in 1986. This was the Chair previously held by famous scientists like J.M. Burgers and J.O. Hinze. Frans' immediate predecessor was Gijs Ooms, who had accepted a position at the research department at the Royal Dutch / Shell oil company a few years earlier. Frans Nieuwstadt had worked at the Royal Dutch Meteorological Institute, where he conducted research on the atmospheric boundary layer. But the chair remained vacant for several years, resulting in a marked decline in research by the laboratory. However, Frans saw the great potential of the laboratory, and he set out to venture into new areas but with a firm footing in his work on atmospheric boundary layers. This was reflected in his inaugural

J. Westerweel · B.-J. Boersma ( $\bowtie)$

Laboratory for Aero and Hydrodynamics, Leeghwaterstraat 21,

2628 CA Delft, The Netherlands

e-mail: B.J.Boersma@tudelft.nl

J. Westerweel

e-mail: J.Westerweel@tudelft.nl 
Fig. 1 Prof. Frans Nieuwstadt, 1946-2005, (Photo: Nout Steenkamp, FMAX/FOM)

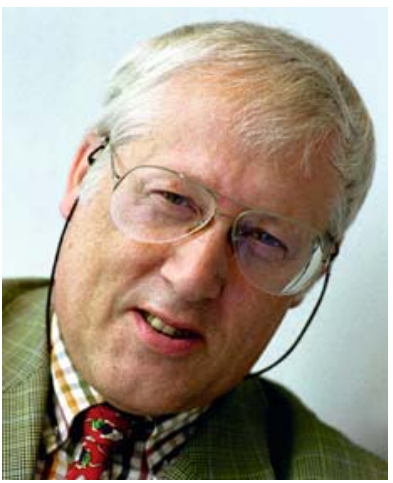

speech, where he laid out his view on research in turbulence (REF). First of all, he was captured by the new insights and findings that were happening in the physics community on the investigation of chaotic systems in non-linear dynamics. It was evident that the observations reported by Lorenz [1], also a researcher with a background in atmospheric science, made it plausible to accept that turbulence was not a disorganized flow state, but that it would contain a degree of organization. Frans realized immediately that chaos theory would not actually solve the problem of turbulence, but that the concepts developed from non-linear dynamics, such as fractal geometry and strange attractor would help to get a better understanding of what turbulence actually is; see Fig. 2. Indeed, turbulence has been a very old problem, dating back to the early observations by Leonardo da Vinci of eddies in a flow and of the problem of linear stability in pipe flow defined by Reynolds [3]. He usually quoted Richard Feynmann, who referred in his famous lecture series to turbulence as the last unsolved problem in classical mechanics:

After obtaining his degree in Aerospace Engineering at the TH-Delft, Frans moved to Caltech where he started working on turbulence. Frans worked under the supervision of Anatol Roshko. It was Roshko, together with Brown, who for the first time described the occurrence of large-scale organized motion in a turbulent mixing layer [2]. These structures were soon referred to as coherent structures. This

Fig. 2 The Lorenz attractor, or Lorenz butterfly, that describes the chaotic motion in a convection flow. This picture also appeared on the cover of Frans' inaugural address

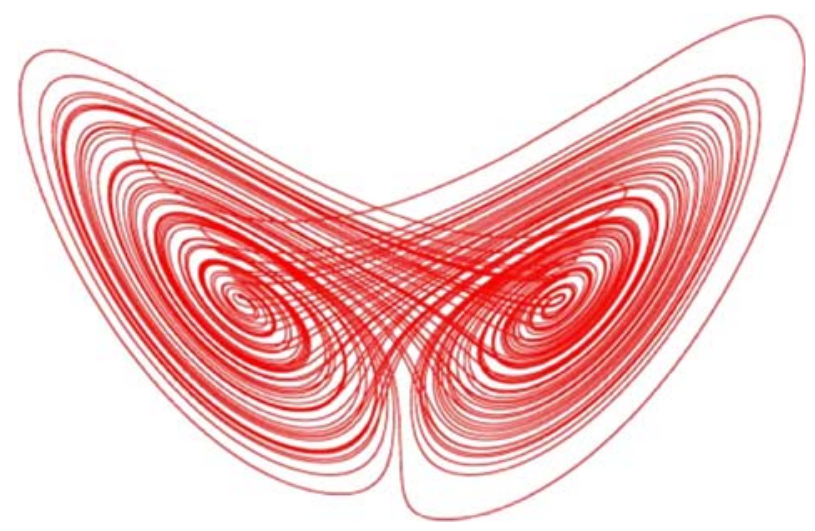


brings us back to Frans' inaugural speech, as he indicated the significance of these structures for the investigation and the understanding of turbulence. After 2 years in the USA he returned to the Netherlands to work on atmospheric turbulence at the Royal Dutch Meteorological Institute, KNMI. Frans obtained his Ph.D. when he was at KNMI, Henk Tennekes was his supervisor. He noticed that the environment of a technical university would put him in an excellent position to venture into new areas. He decided to study turbulent boundary layers, conveniently close to the atmospheric boundary layer, and to use his position at the Delft Technical University to develop new methods to study turbulent flows. He observed that the rapid growth of computing power of supercomputers would make it possible to perform large eddy simulations (LES) and even direct numerical simulations (DNS). Both methods solve the Navier-Stokes equations, although in LES the smallest scales (where the turbulence is in a near-isotropic state) are modeled, whereas in a DNS all scales are resolved and no turbulence modeling is applied. His first use of LES was the simulation of an atmospheric boundary layer. At the same time, it became evident to him that is was necessary to develop new experimental methods that would be capable of measuring these coherent flow structures mentioned before. In the mid-80's the common experimental methods were hot-wire anemometry (HWA) and laser-Doppler anemometry (LDA). Both methods are single-point methods, which - in Frans' view - are fundamentally unsuited to capture the instantaneous spatial structures that were observed in flow visualizations. He was inspired by work of Bert Hesselink at Stanford University, ${ }^{1}$ who used modern image processing methods to obtain quantitative information from flow visualization images, which until then only gave qualitative information of coherent flow structures. Frans obtained an innovation grant of the TU Delft which would make it possible to hire a Ph.D. student and to acquire modern image acquisition and processing hardware.

The development of modern numerical and experimental methods and the combination of concurrent numerical and experimental investigation shows Frans' visionary view on how to tackle the problem of investigating contemporary problems in flow turbulence. This has been the foundation of his success in which he brought together these two disciplines within one laboratory.

Frans' initial aim was to focus on boundary layers. The laboratory was equipped with several wind tunnels that were suited for the investigation of turbulent boundary layers. Arno Brand was his first Ph.D. student in the laboratory who started out on using image processing methods for the investigation of coherent flow structures in a turbulent boundary layer. The idea was to use mild forcing by means of injection to stimulate the formation of hairpin vortices and investigate the 'bursting process' [26]. At the same time Luc van Haren, who had joined Frans from the KNMI, worked on the development and application of LES for the atmospheric boundary layer.

In a short time four new Ph.D. students started in 1989 to work in the laboratory: Jerry Westerweel started to work on further development of digital images processing, which led to the development and application of particle image velocity in the laboratory [27]; Jack Eggels started to work on DNS and LES of swirling and nonswirling pipe flow [29]; Mathieu Pourquie began to work on the implementation of scalar transport in a LES of a turbulent flow [31]; and Fons Alkemade who began

${ }^{1}$ Bert Hesselink and Frans were colleagues at Caltech. 
to explore the possibilities of representing coherent flow structures by the so-called 'vorton method' [30].

The DNS of pipe flow was inspired by the publication of Kim, Moin and Moser (KMM) of a DNS in channel flow [23]. The computational grid for a channel flow is straightforwardly implement as a rectangular grid, but Frans figured that a pipe flow, which is naturally represented in a cylindrical coordinate system, would be a geometry that has more relevance to industrial applications. The challenge was to define a grid that does not suffer from the singularity at the pipe axis. The results of the DNS showed remarkably good agreement with several different measurements, see for instance Fig. 3. The results of this work were published in a 1994 JFM paper, jointly with collaborators in Germany, the USA and Canada [5]. Over the years, this manuscript has been cited frequently, and this DNS has become a test case for many other studies. It is interesting to note that the Reynolds number of 5,300 was chosen in accordance to the KMM channel flow conditions: the Reynolds number based on the friction velocity and pipe radius is 180, which is identical to the same Reynolds number in the KMM simulation. This is equivalent to a Reynolds number of 5,300 when based on the bulk velocity and pipe diameter, and this Reynolds number appears frequently in both experimental and numerical studies.

\section{Turbulence in Cylindrical Coordinates}

The pipe flow DNS made Frans' focus shift from boundary layers to flows that are most naturally represented in cylindrical coordinates. Two new Ph.D. students

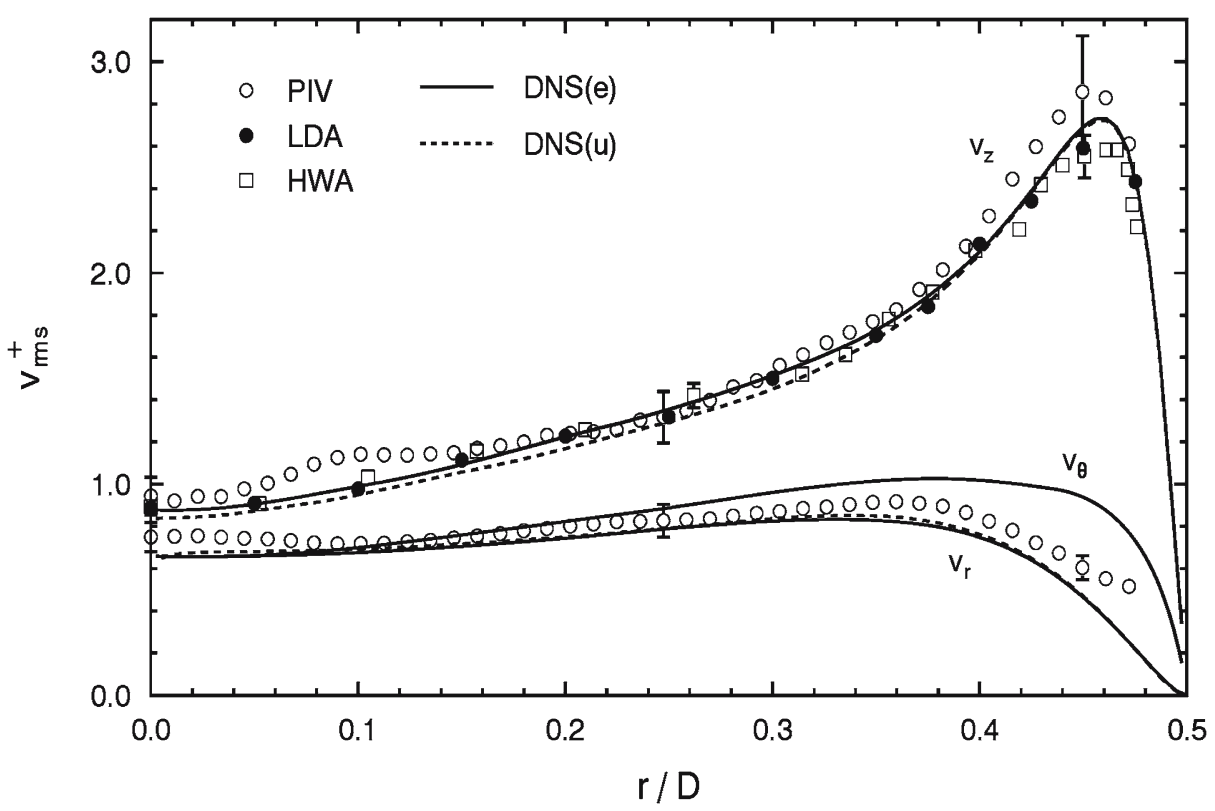

Fig. 3 The root mean square of the three velocity components in a pipe flow. Lines are the results of the DNS and the symbols are the results of different experiments 
started to work in the laboratory: Aswin Draad and Jaap den Toonder. Aswin Draad was investigating the laminar-turbulent transition in a pipe for non-Newtonian fluids [35]. This work was related to the possible exploitation of delaying transition to turbulence in the flow of non-Newtonian drilling fluids in oil exploration. The second $\mathrm{Ph}$.D. student, Jaap den Toonder, was to investigate polymer drag reduction in pipe flow by both numerical and experimental methods [34]. A result of the calculations of Jaap is shown in Fig. 4. Although there was a pipe flow facility available in the laboratory, it was considered to be inadequate for the experimental part of Aswin Draad's investigation. As the development length for laminar flow of a nonNewtonian flow in a pipe was not known (some references in literature reported development lengths of more than 500 pipe diameters), it was decided to build a 40$\mathrm{mm}$ diameter pipe with a total length of $28 \mathrm{~m}$, i.e. 700 pipe diameters; this was just $2 \mathrm{~m}$ short of the total length of the basement where the pipe was built. A photograph of the pipe used by Aswin and Jaap is shown in Fig. 5.

The design and construction of this pipe took about 1 year. It was made of transparent Plexiglas, so that it was suited for the use of optical diagnostics, like LDA and PIV. When the first measurements were taken, it came to a big surprise that the laminar velocity profile that was measured did not have the textbook parabolic shape, but that it was distinctly skewed, see Fig. 6. Long and careful thought revealed that the only explanation was that a Coriolis force acts on the flow in the pipe [8]. Generally, Coriolis forces are thought to be extremely small and insignificant, as demonstrated in the famous instruction movie on vorticity by Shapiro. However, at a moderate Reynolds number of 3,000, the mean transit time of a fluid element through the pipe is more than 6 min (with fluid elements near the pipe wall taking considerably longer, of course), which is sufficiently long for a small force to make a big difference. A careful calculation of the effect matched excellently with the observed skew [8].
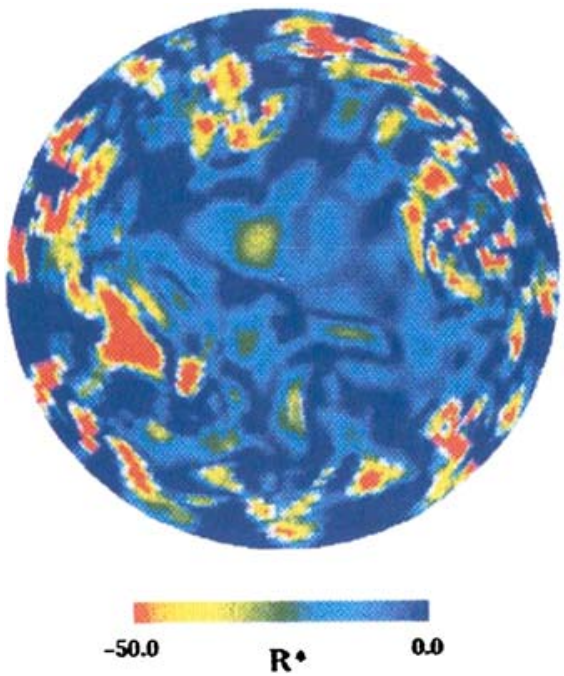
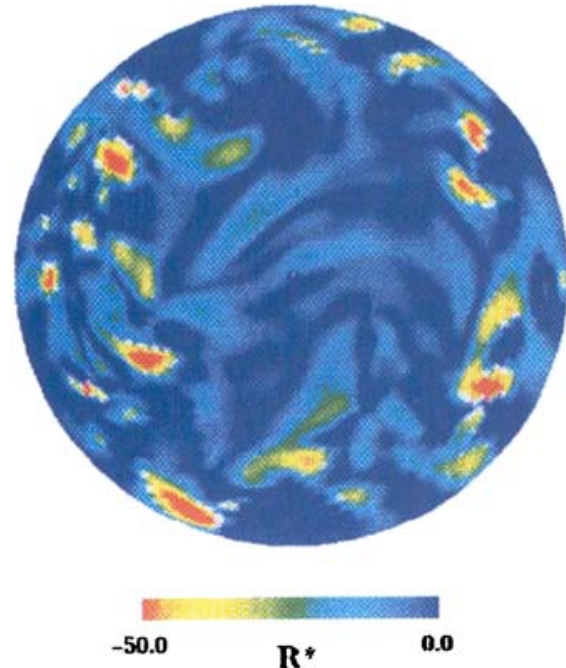

Fig. 4 Regions of high polymer extension in a turbulent pipe flow. Left: Newtonian flow, right: polymer flow 


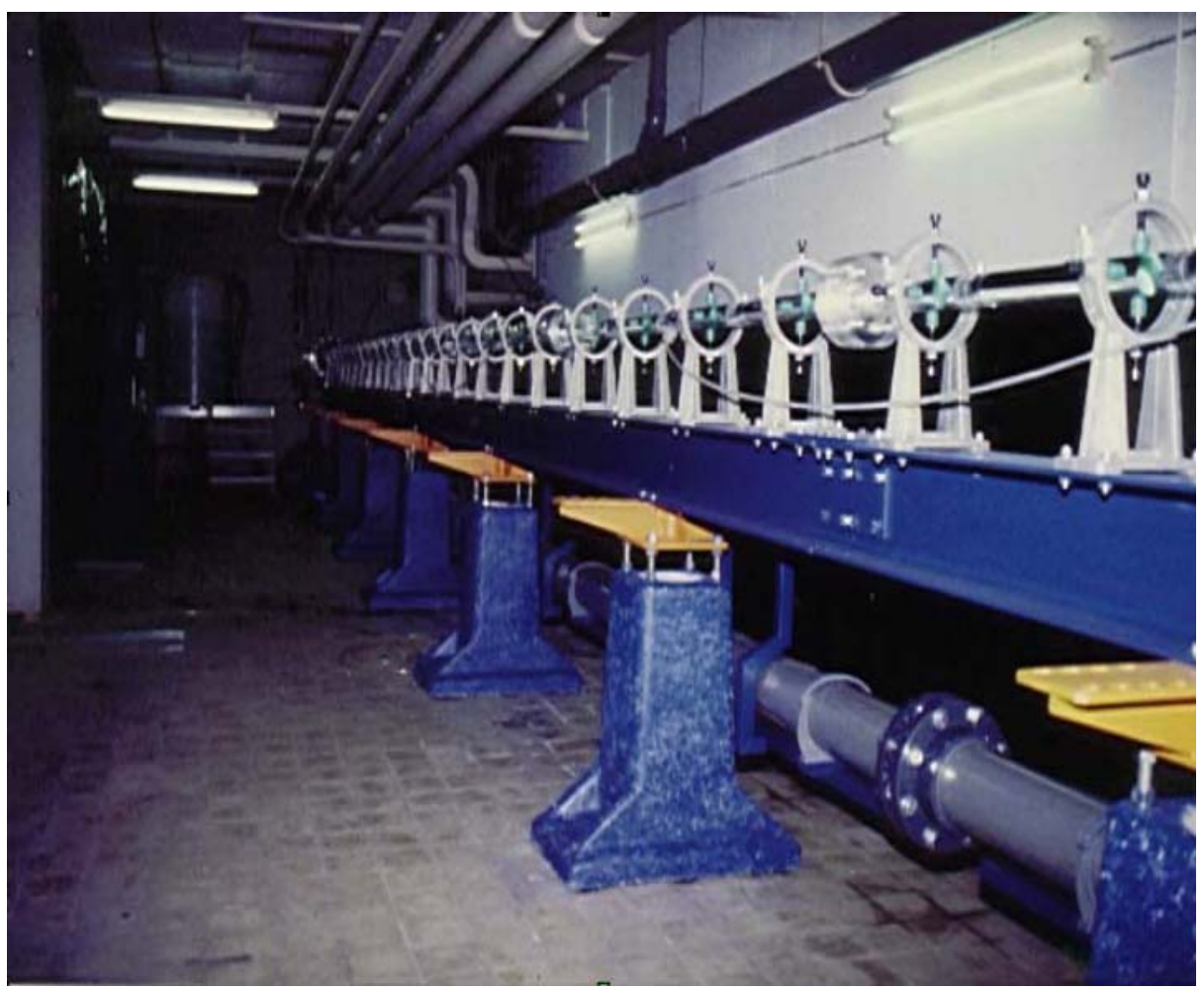

Fig. 5 The long pipe flow facility in the basement of the old laboratory

Despite this effect, the pipe flow facility was well suited for the investigation of laminar and turbulent pipe flow. It was demonstrated that the flow remained laminar over the full length of the pipe up to a Reynolds number of 60,000 [7, 35].

Concurrently with this work, Jaap den Toonder investigated the phenomenon of drag reduction when long polymers are added to the fluid. This can reduce the friction by up to $70 \%$. Although this has been reported by many investigators, the exact physical mechanism of how these polymers affect the turbulence remained elusive [6, 34].

The investigation of pipe flow led to a discussion between Frans Nieuwstadt and Franz Durst from Erlangen, who both were presenting results on pipe flow in the same session at a conference. Frans showed how the DNS revealed a diverging skewness and flatness in the near-wall region, although this was not observed in experimental results and could be DNS artifacts. Upon return to the laboratory, Jaap den Toonder set out to take LDA measurements in the pipe. Frans had figured that rare events with a large amplitude, say a velocity fluctuation of five times the standard deviation that occurs once in every $10^{5}$ integral times would make a significant contribution to higher order velocity moments [20]; however such an event would remain undetected in a measurement that rejects all events with fluctuations beyond 2 times the standard deviation. Indeed, after a total measurement time of $6 \mathrm{~h}$ such an event was detected in the unfiltered LDA time series that strongly resembled such 


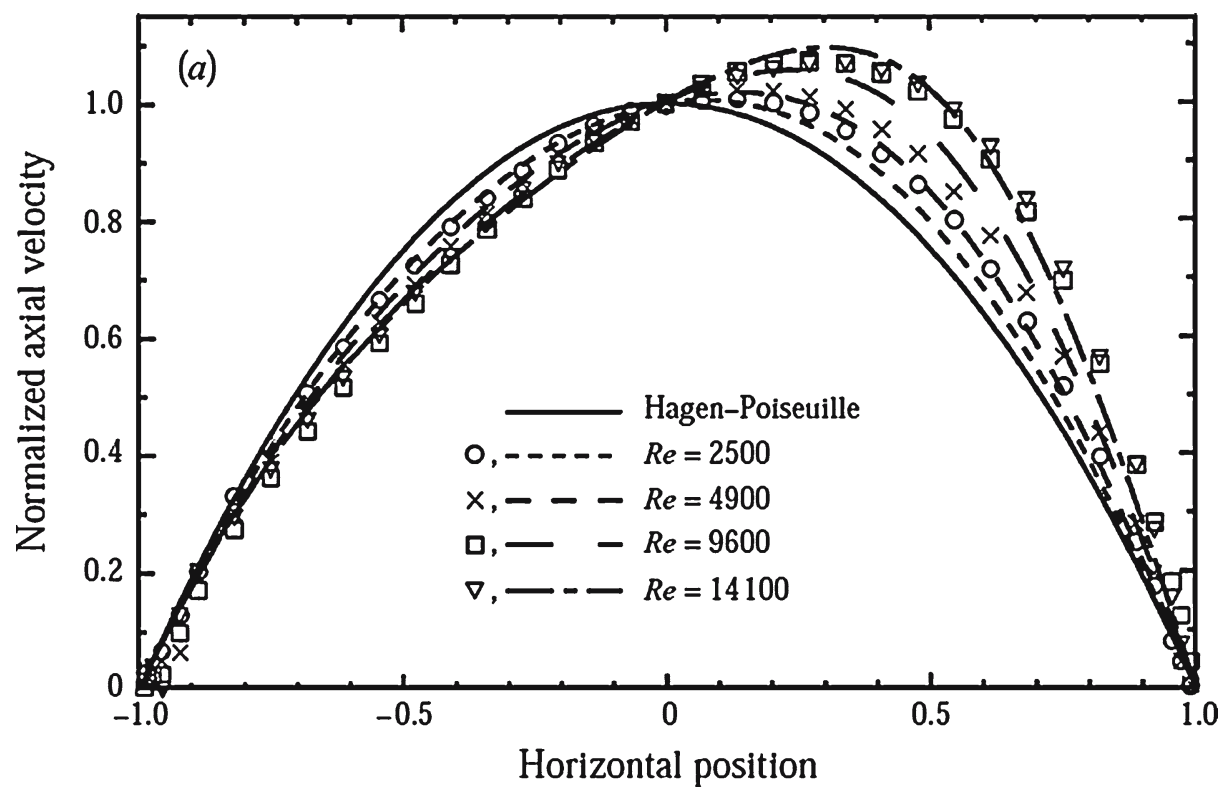

Fig. 6 The effect of the Coriolis force on laminar pipe flow

rare events found in a DNS; see Fig. 7. This is a typical example of the concurrent numerical and experimental investigations that Frans favored.

Frans' interest in drag reduction also resulted in an investigation of drag reduction over surfaces with so-called riblets, i.e. streamwise grooves that mimic the skin of
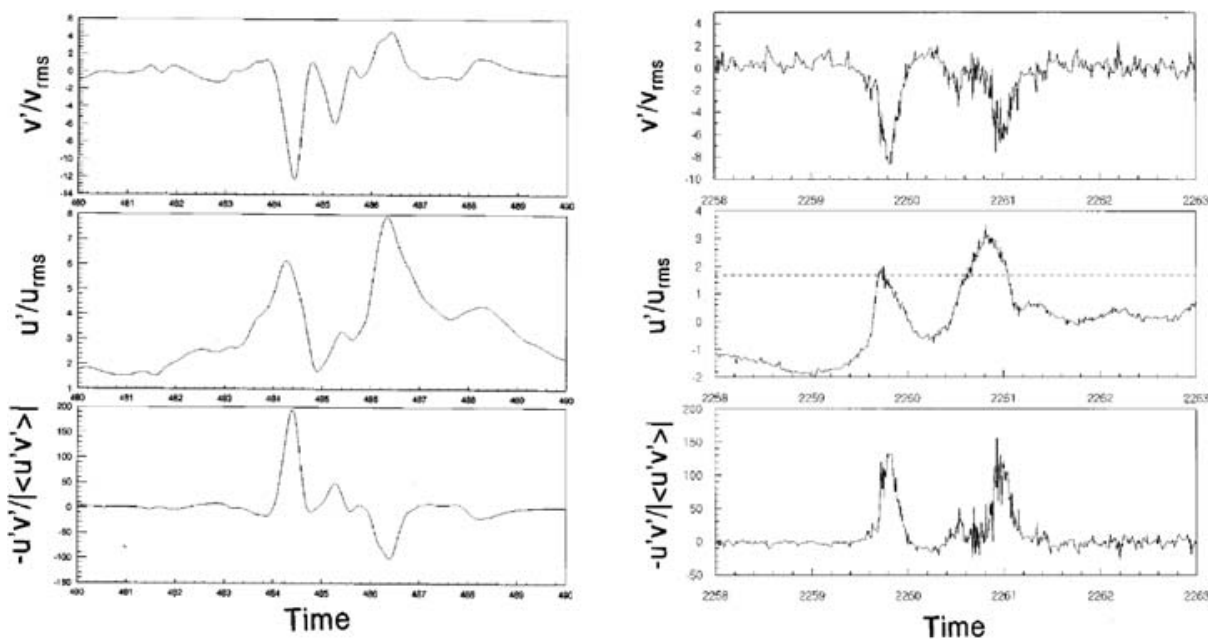

Fig. 7 Selected rare events in the near-wall region of a pipe observed in a DNS (left) and measured with LDA in a pipe (right); these rare events explain the very high skewness and kurtosis levels toward the wall in turbulent pipe flow. From: Xu et al. [20] 
certain sharks. Jacobiene van der Hoeven had worked with Dietrich Bechert in Berlin, and returned to Delft to do her Ph.D. on the changes in the turbulent flow structure over smooth and riblet surfaces [42].

The interest in investigating turbulent pipe flow extended to the investigation of turbulent flows in an axial phase separator, which was another example of fundamental research with a clear connection to a practical application; in this case the development of such flow separators is important for oil exploration as axial flow separators have a much smaller pressure drop than conventional tangential flow separators. Yet, the problem is that conventional turbulence models perform poorly in strongly swirling flows. This investigation was carried out by Maarten Dirkzwager [36]. A photograph of the axial separator developed by Maarten is shown in Fig. 8.

Another theoretical investigation with a clear application was related to flow metering of pipe flows. In a so called electromagnetic flow meter a magnetic field is applied to the flow. In a weakly conduction fluid, like for instance water, an electric potential will be introduced. This potential is related to the flow rate through the pipe. For laminar flow this relation was well understood, but this was not the case of turbulent flows, which is the more common flow state encountered in industrial situations. The behavior of an electromagnetic flowmeter in a turbulent flow was investigated in the PhD project of Bendiks Jan Boersma [37].

After the successful studies of turbulent pipe flow, Frans attacked again the complex problem of laminar-turbulent transition in pipe flows, which was started a few years before by Aswin Draad. Cas van Doorne continued the work started by Aswin Draad. The objective was to develop an experiment that would investigate the transition in pipe flow induced by a periodic 'blowing and suction' that was

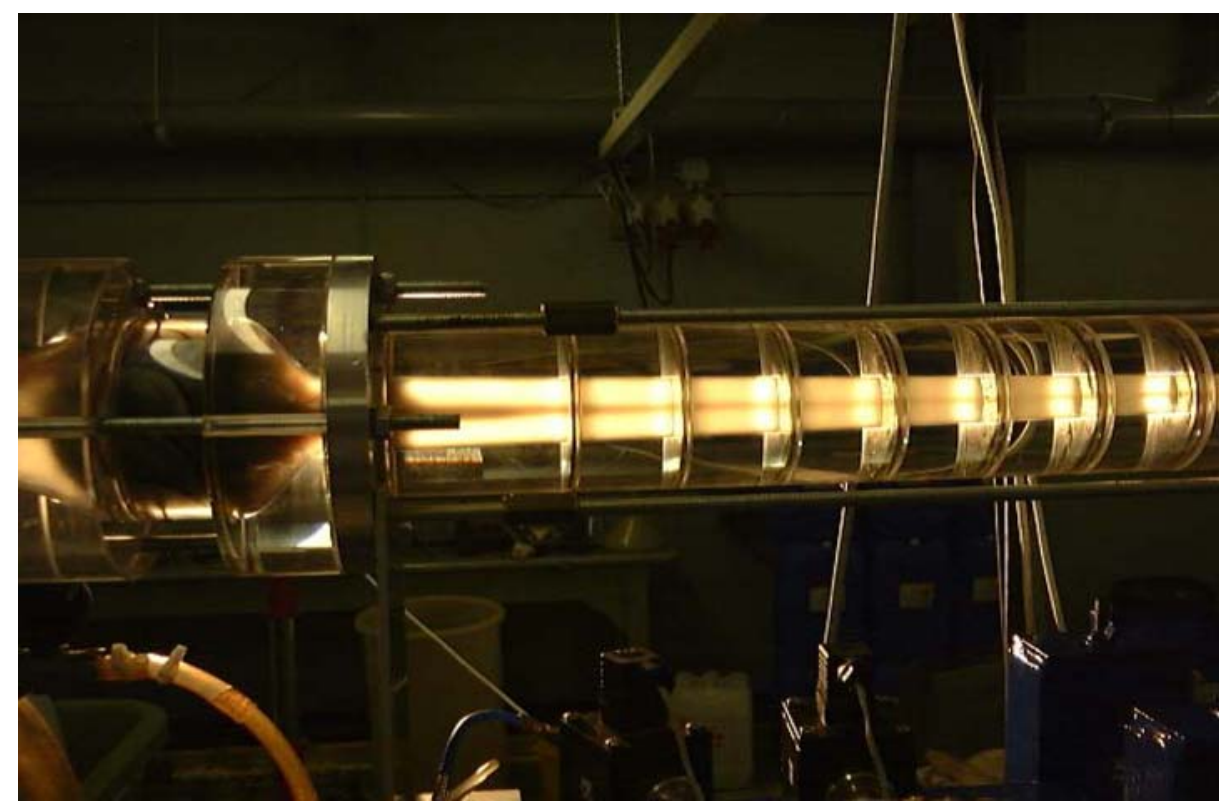

Fig. 8 The axial separator as developed by Maarten Dirkzwager. Flow is going from left to right 空 Springer 

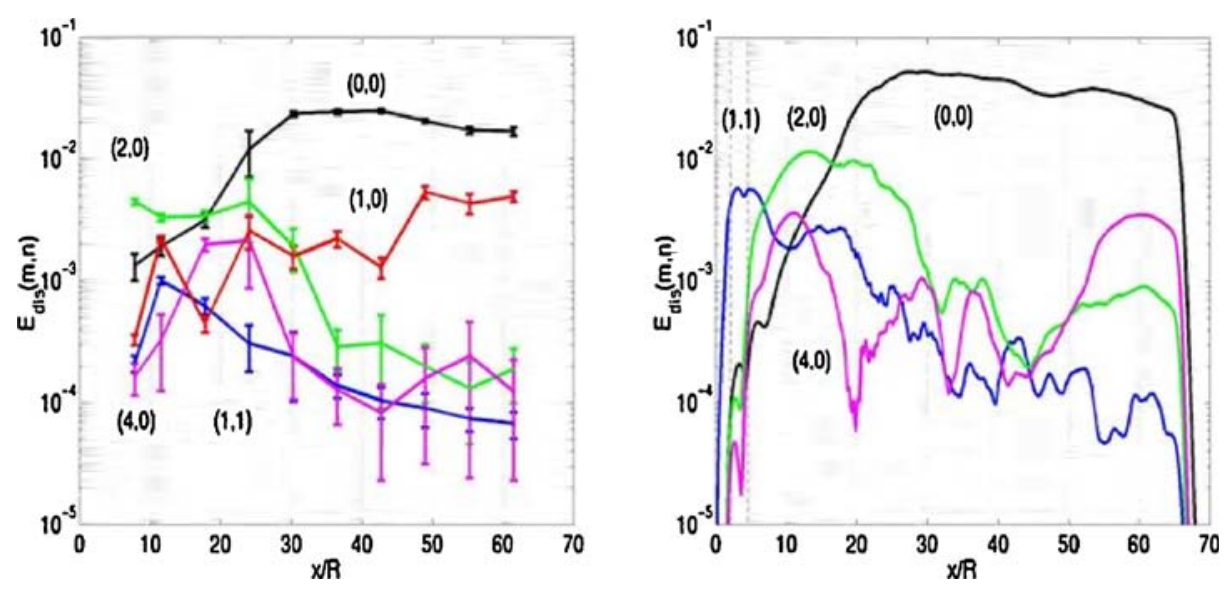

Fig. 9 The spatial evolution of the disturbance energy for various Fourier modes. On the left is the experimental result of Cas van Doorne, on the right is the result of the calculations by Isabella Gavarini

investigated previously by means of DNS [14]. At the same time, Ph.D. student Isabella Gavarini approached the same transition problem from the theoretical side, and she was able to predict many of the experimental findings of Cas van Doorne $[12,49]$; This is illustrated in Fig. 9 where we show the spatial evolution of the disturbance energy in terms of Fourier modes.

At the time Cas van Doorne had completed his measurements Bruno Eckhardt from the University of Marburg presented at a seminar in the lab his latest theoretical work on traveling wave solutions in pipe flow [24]. These new solutions could mean a breakthrough towards solving the long-lasting problem of the transition to turbulence in pipe flow, although the method used to find these structures was rather complex and intricate, especially since these traveling wave solutions were highly unstable. However, to everyones surprise and delight these structures could actually be observed in the experimental data, see Fig. 10; these experimental findings supported this new direction in the theoretical investigation of transition in pipe flow, and were published in Science [25]. This publication received a lot of attention, both in academia and in the public press.

Fig. 10 Instantaneous flow structure measured with stereoscopic PIV in a turbulent puff at $\mathrm{Re}=2,000$ (left) and the cross-sectional slice through a $C_{3}$ symmetric streamwise travelling wave observed numerically at $\mathrm{Re}=1,250$; from: Hof et al. [25]
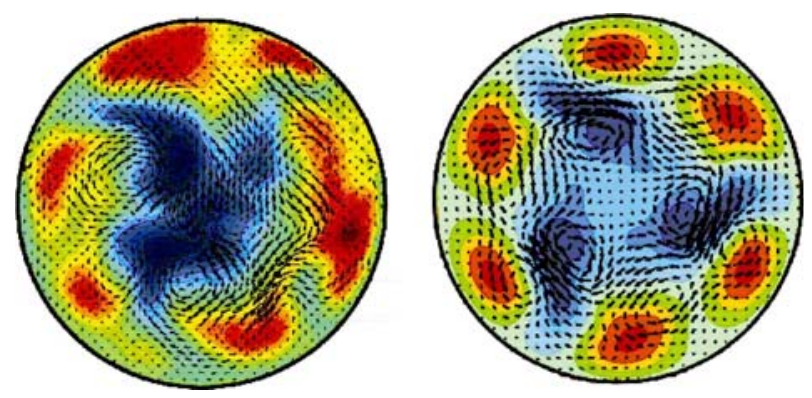


\section{New Directions}

Over the years the focus of the research had shifted in a new direction, which Frans used to refer to as 'turbulence plus'. The principal interest was to investigate turbulence at a fundamental level, but also to consider turbulence and its role in other processes.

He became interested in the interaction between turbulence and small particles, or dispersed turbulent flows. Such flows occur both in industry and in the natural environment; In industrial processes very often catalysts occur as small particles (in order to maximize the total surface area) in highly turbulent flows, and in the natural environment we find this type of flow in the case of sediment transport in rivers and estuaries. A fundamental investigation, carried out by Lex Mollinger, was to experimentally investigate the lift force on a very small particle in a turbulent boundary layer. The measurement device developed by Lex Mollinger consisted of a very small cantilever on which a small particle of $100 \mu \mathrm{m}$ was glued. With a small laser system Lex Mollinger measured the displacement of the cantilever, and he was able to measure the very small lift force on the particle of about $10^{-8}$ Newton [9, 32]. Later on this measurement technique was used in another project [15].

Inspired by the experimental work on particles in turbulent flow, Frans started a numerical investigation on the dynamics of particles in wall bounded turbulent flow. This project was carried out by Bas van Haarlem [18]. After the successful study of particles in wall bounded flow Bas van Haarlem also investigated the dynamics of particles in isotropic turbulence [41]. His observation that aerosols in the atmospheric boundary layer could be trapped inside small vortices and could be responsible for sudden rainfall during periods of rather clear sky got a lot of international exposure, ranging from the Frankfurter Allgemeine Zeitung to CNN.

Another ongoing research topic was the work on polymer drag reduction started by Jaap den Toonder. This work was continued by Piotr Ptasinski, who carried out detailed LDA measurement and rheological measurements on polymer suspensions in turbulent pipe flows. In his experiment he observed a drag reduction of roughly $70 \%$, similar to the results obtained by Jaap den Toonder a few years earlier. Piotr also performed numerical simulations of turbulent wall bounded flow. With more advanced viscoelastic models than used previously by Jaap den Toonder, Piotr was able to reproduce the results of his LDA measurements [10, 46]. Based on the work of Piotr two other Ph.D. projects were started: The Ph.D. students working on these new projects, Chiara Witteman-Tesauro and Jurriaan Gillissen will complete their Ph.D. soon.

Another area of interest was turbulent mixing. This is again a good example of concurrent experimental and numerical work. Lourens Aanen studied turbulent mixing of fluorescent dye emitted from a point source in a turbulent pipe flow by means of a combination of PIV and laser-induced fluorescence (LIF)[47]. This made it possible to experimentally determine the turbulent scalar fluxes from the simultaneously measured fluctuations of the velocity and the concentration. In concurrence with this experimental investigation, Geert Brethouwer carried out direct numerical simulations of passive scalars in turbulent flows, first building on the work by Mathieu Pourquie performed some years ago. Furthermore, he carried out very detailed numerical simulations of mixing of passive scalars in isotropic turbulence [13, 44]. Figure 11 presents a typical result of Brethouwer's isotropic turbulence simulations. 

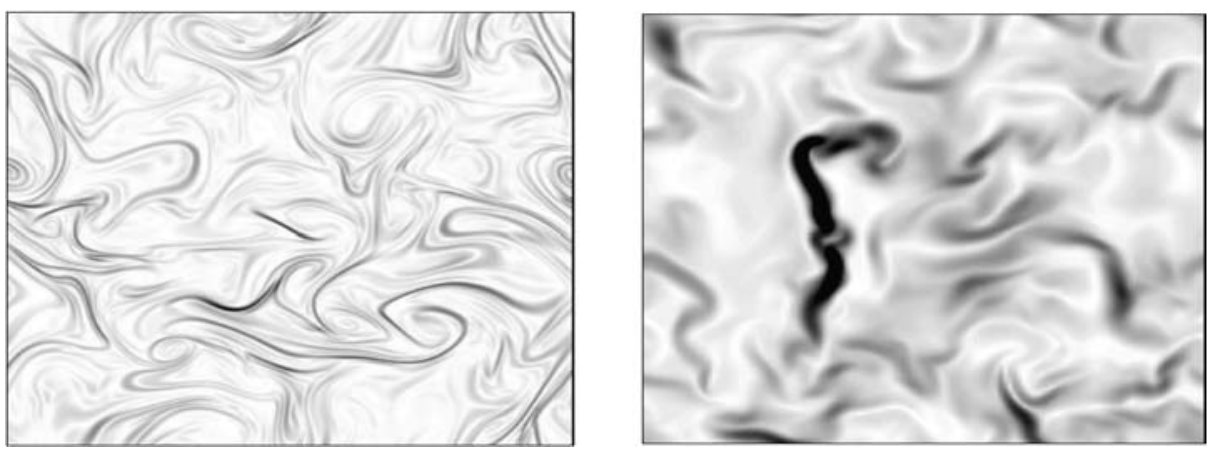

Fig. 11 The norm of the scalar gradient on a two-dimensional plane at Schmidt number $\mathrm{Sc}=25$, a Taylor Reynolds number $\operatorname{Re}_{\lambda}=46$ (left) and a Schimdt number $\mathrm{Sc}=0.1$, and a Taylor Reynolds number $\operatorname{Re}_{\lambda}=95$ (right)

Alja Vrieling continued the work of Geert Brethouwer and looked at selectivity of chemical reactions in a turbulent flow. Apart from her work on selectivity Alja Vrieling was also involved in a study on forced convection [11, 48]. This work was inspired by Julian Hunt, who was a long time friend and colleague of Frans Nieuwstadt.

By the work of Alja Vrieling, Frans got interested in the effect of sharp temperature gradients on turbulence. In the forced convection studies the temperature differences remained fairly small. The logical step was to look for problems with large temperature gradients, i.e. flows outside the Boussinesq regime. He started with an investigation of premixed turbulent combustion. He was not interested in the combustion, but purely on the effect of turbulence dynamics on the interface between the hot fluid and the cold fluid. In his PhD work Theo Treurniet performed direct numerical simulations of premixed turbulent combustion using a so-called

Fig. 12 Turbulence, visualized by the enstrophy, separated by a flame front (indicated by the solid line), the fluid on the left side is cold and on the right side is hot

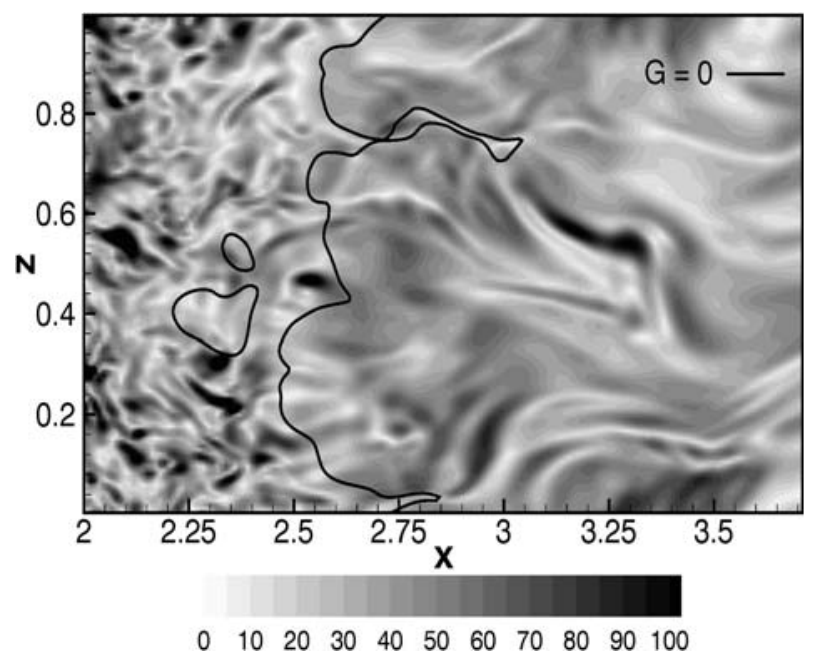

Springer 
$G$-equation, or level-set approach [45]. A typical result of Treurniet's direct numerical simulations is shown in Fig. 12. The approach, based on the $G$-equation, may be considered as a very crude approach for premixed turbulent combustion. However, it was demonstrated by Theo Treurniet and Frans that this approach is very useful for studying the dynamics of the hot-cold interface [17].

Frans' last Phd student was Wim Paul Breugem who performed very detailed numerical simulations of the turbulent flow over and in a porous layer [50]. In 2003 and 2004 Wim-Paul Breugem performed the largest direct numerical simulation ever done in the laboratory. For his simulations he used 100 million grid points; even with today's standards this is an enormous amount of grid points. One of WimPaul Breugem's main results is shown in Fig. 13. This investigation showed that the conventional scaling of the turbulent boundary layer with a von Karman constant of 0.4 is not valid for the flow over a porous layer [16]. First, Frans questioned Wim-Paul Breugem's findings, but after considerable thought and many discussions he agreed with Wim-Paul. The discussion about the consequences of these results on the scaling of turbulent flow over a porous layer continued long after Wim-Paul had successfully defended his Ph.D. thesis.

\section{Other Topics}

Over the years Frans kept a strong interest in atmospheric research, and he kept working on this topic in his own spare time. He wrote several influential papers about the atmospheric boundary layer with his former colleagues from the atmospheric research community $[4,22]$. Several of the Ph.D. projects carried out in the group were inspired by Frans' background in atmospheric turbulence, for instance the investigation of natural convection by Ton Versteegh [39], the combustion work by Theo Treurniet, and the forced convection studies performed by Alja Vrieling. During his period in Delft he also supervised two Ph.D. students who obtained their Ph.D. on a purely atmospheric subject. Hans Cuijpers, who was formally appointed at the Royal Dutch Meteorological Institute, performed large eddy simulations of

Fig. 13 The flow over a porous wall in the form of an array of cubes. The computational grid for the simulation contained 100 million grid points

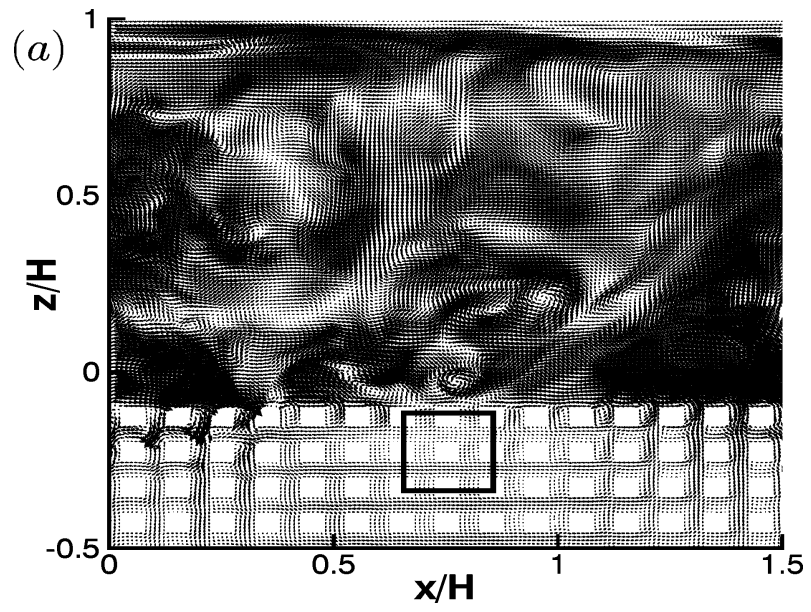


the formation of cumulus clouds in the convective atmospheric boundary layer [28]. A few years later John Meeder performed numerical simulations of the convective atmospheric boundary layer to study the dispersion process of reactive plumes [38].

His interest in the fundamental aspects of turbulence was also aimed at the investigation of some of the fundamental axioms of turbulence. He was interested to investigate one of the fundamental assumptions of turbulence: does the turbulence microscale become isotropic when the Reynolds number becomes very large? In view of this, Arjan van Dijk investigated the use of hot-wire measurements and the interpretation of one-dimensional spectra in relation to the full three-dimensional turbulence spectrum [40].

The interest of Frans Nieuwstadt in fluid mechanics was much broader than turbulence. He also supervised the Ph.D. work of Rob Uittenbogaard and Jan Verhelst [21]. Rob Uittenbogaard, an employee of WL-Delft Hydraulics wrote a $\mathrm{Ph} . \mathrm{D}$. thesis about his work on internal waves in stratified estuarine tidal flows [33]. Jan Verhelst, who had originally another Ph.D. adviser, performed experiments and computations on the visco-elastic flow past circular cylinders [43].

\section{Epigraph}

Under the guidance of Frans Nieuwstadt the Laboratory for Aero \& Hydrodynamics became one of the most prominent research groups in the area of fluid mechanics and turbulence in the Netherlands. He was very proud of the 2004 Science publication, which for him indicated the achievement that his research had reached 'world class' level.

His involvement in fluid mechanics and turbulence research was not limited to the activities within the laboratory; he was instrumental in the formation of the J.M. Burgers Center, the Netherlands research school for fluid dynamics, of which Gijs Ooms is the current scientific director. The J.M. Burgers Center strongly promoted the area of fluid mechanics in the Netherlands, and it created an environment for excellent research in fluid dynamics. Within the J.M. Burgers Center the number of Ph.D. students has been growing steadily, and is considered as an example for other countries and disciplines.

Frans created an open and informal environment in the group. His view on leading a large research group was inspired by Anatol Rosko at Caltech. Frans created an open atmosphere where students got the opportunity to develop themselves to independent scientists and also to develop their personal skills. There was always the possibility for visitors to work in the laboratory, and this added to the international atmosphere in the group. He very much stimulated students to travel to other groups, and gain experience and knowledge in a different environment.

When Frans was appointed at the fluid mechanics chair he also more or less inherited the position of editor-in-chief for Applied Scientific Research. At that time this was a journal without a clear scope and a modest visibility (expressed in terms of the impact factor). Over the years Frans converted this journal into a journal devoted to fluid mechanics. Fairly recently the name of this journal has been changed into Flow, Turbulence \& Combustion. When Frans passed away, his former colleague Kemo Hanjalic took over the position as editor-in-chief. 
Apart from research Frans was also strongly involved in educational activities. He single handedly taught the fluid mechanics and heat-transfer course for the Bachelor program of Mechanical Engineering. Furthermore, he wrote a Dutch book about turbulence, called turbulentie [51] which was loosely based on Tennekes and Lumley [52]. His book has been used for many years as guideline for the turbulence course in Delft but also at the other two technical universities in the Netherlands. In 2002 Frans was awarded the 'Leermeesterschaps' prize, issued annually by the Delft University of Technology, as a recognition for his excellence in teaching and research. He said this prize was dearest to him, since it is the students who have a strong vote in the nomination, and not a committee of "gray-haired old men", to which group he also counted himself.

The former office of Frans Nieuwstadt is now converted into a library and meeting room, containing all the important fluid mechanics journals and books. In this room there is also a collection of his articles and the Ph.D. theses he supervised. His devotion to his students and their research, his keen and thorough knowledge of fluid mechanics, and his great warmheartedness is remembered by everyone who had the privileged to work with him.

\section{References}

1. Lorenz, E.N.: Deterministic nonperiodic flow. J. Atmos. Sci. 20, 130-141 (1963)

2. Brown, G.L., Roshko, A.: On density effects and large structure in turbulent mixing layers. J. Fluid Mech. 64, 775-816 (1974)

3. Reynolds, O.: An experimental investigation of the circumstances which determine whether the motion of water shall be direct or sinuous, and of the law of resistance in parallel channels. Philos. Trans. R. Soc. Lond. 174, 935-982 (1883)

4. Nieuwstadt, F.T.M., Mason, P.J., Moeng, C.H., Schumann, U.: Large-eddy simulation of the convective boundary layer - a comparison between four computer codes. Symposium on Turbulence Shear Flows, Munich, Germany (1991)

5. Eggels, J.G.M., Unger, F., Weiss, M.H., Westerweel, J., Adrian, R.J., Friedrich, R., Nieuwstadt, F.T.M.: Fully developed turbulent pipe flow: a comparison between direct numerical simulation and experiments. J. Fluid Mech. 268, 175-209 (1994)

6. den Toonder, J.M.J., Hulsen, M.A., Kuiken, G.D.C., Nieuwstadt, F.T.M.: Drag reduction by polymer additives in a turbulent pipe flow: numerical and laboratory experiments. J. Fluid Mech. 337, 193-231 (1997)

7. Draad, A.A., Kuiken, G.D.C., Nieuwstadt, F.T.M.: Laminar-turbulent transition in pipe flow for Newtonian and non-Newtonians fluids. J. Fluid Mech. 377, 267-312 (2000)

8. Draad, A.A., Nieuwstadt, F.T.M.: The Earth's rotation and laminar pipe flow J. Fluid Mech. 361, 297-308 (2000)

9. Mollinger, A.M., Nieuwstadt, F.T.M.: Measurement of the lift force on a particle fixed to the wall in the viscous sublayer of a fully developed turbulent boundary layer. J. Fluid Mech. 316, 285-306 (1996)

10. Ptasinski, P.K., Boersma, B.J., Nieuwstadt, F.T.M., Hulsen, M.A., van den Brule, B.H.A.A., Hunt, J.C.R.: Turbulent channel flow near maximum drag reduction: simulations, experiments and mechanisms. J. Fluid Mech. 490, 251-291 (2003)

11. Hunt, J.C.R., Vrieling, A.J., Nieuwstadt, F.T.M.: The influence of the thermal diffusivity of the lower boundary on eddy motion in convection. J. Fluid Mech. 491, 183-205 (2003)

12. Gavarini, M.I., Bottaro, A., Nieuwstadt, F.T.M.: The initial stage of transition in pipe flow: role of optimal base-flow distortions. J. Fluid Mech. 517, 131-165 (2004)

13. Brethouwer, G., Hunt, J.C.R., Nieuwstadt, F.T.M.: Micro-structure and Lagrangian statistics of the scalar field with mean gradient in isotropic turbulence. J. Fluid Mech. 474, 193-225 (2003)

14. Ma, B., van Doorne, C.W.H., Zhang, Z., Nieuwstadt, F.T.M.: On the spatial evolution of a wall-imposed periodic disturbance in pipe Poisseuille flow at Re=3000. J. Fluid Mech. 398, 181-224. (2000) 
15. Muthanna, C., Nieuwstadt, F.T.M., Hunt, J.C.R.: Measurements of the aerodynamic forces on a small particle attached to a wall. Exp. Fluids 39, 455-463 (2005)

16. Breugem, W.P., Boersma, B.J., Uittenbogaard, R.E.: The influence of wall permeability on turbulent channel flow. J. Fluid Mech. 562, 35-72 (2006)

17. Treurniet, T.C., Nieuwstadt, F.T.M., Boersma, B.J.: Direct numerical simulation of homogeneous turbulence in combination with premixed combustion at low Mach number modeled by the G-equation. J. Fluid Mech. 565, 25-62 (2006)

18. B. van Haarlem, Boersma, B.J., Nieuwstadt, F.T.M.: Direct numerical simulation of particle deposition onto a free-slip and no-slip surface, Phys. Fluids 10, 2608-2620 (1998)

19. Boersma, B.J., Brethouwer, G., Nieuwstadt, F.T.M.: A numerical investigation on the effect of the inflow conditions on the self-similar region of a round jet. Phys. Fluids 10, 899-909 (1998)

20. Xu, C., Zhang, Z., den Toonder, J.M.J., Nieuwstadt, F.T.M.: Origin of high kurtosis levels in the viscous sublayer: Direct numerical simulations and experiments. Phys. Fluids 8, 1938-1944 (1996)

21. Verhelst, J.M., Nieuwstadt, F.T.M.: Visco-elastic flow past circular cylinders mounted in a channel: experimental measurements of velocity and drag. J. Non-Newton. Fluid Mech. 116, 301-328 (2004)

22. Nieuwstadt, F.T.M., Duynkerke, P.: Turbulence in the atmospheric boundary layer. Atmos. Res. 40, 111-142 (1996)

23. Kim, J., Moin, P., Moser, R.: Turbulence statistics in fully developed channel flow at low Reynolds number. J. Fluid Mech. 177, 133-166 (1987)

24. Faisst, H., Eckhardt, B.: Traveling waves in pipe flow. Phys. Rev. Lett. 91, 224502 (2003)

25. Hof, B., van Doorne, C.W.H., Westerweel, J., Nieuwstadt, F.T.M., Faisst, H., Eckhardt, B., Wedin, H., Kerswell, R.R., Waleffe, F.: Experimental observation of nonlinear traveling waves in turbulent pipe flow. Science 305, 1594-1598 (2004)

26. Brand, A.J.: The turbulent boundary layer: spanwise structure, evolution of low-velocity regions and response to artificial disturbances. Ph.D. thesis, TU-Delft, The Netherlands (1992)

27. Westerweel, J.: Digital particle image velocimetry: theory and application. Ph.D. thesis, TU-Delft, The Netherlands (1993)

28. Cuijpers, J.W.M.: Large-eddy simulation of cumulus convection. Ph.D. thesis, TU-Delft, The Netherlands (1994)

29. Eggels, J.G.M.: Direct and large eddy simulation of turbulent flow in a cylindrical pipe geometry. Ph.D. thesis, TU-Delft, The Netherlands (1994)

30. Alkemade, A.J.Q.: On vortex atoms and vortons. Ph.D. thesis, TU-Delft, The Netherlands (1994)

31. Pourquie, M.J.B.M.: Large-eddy simulation of a turbulent jet. Ph.D. thesis, TU-Delft, The Netherlands (1994)

32. Mollinger, A.M.: Particle entrainment. Measurement of fluctuating lift force. Ph.D. thesis, TU-Delft, The Netherlands (1995)

33. Uittenbogaard, R.E.: The importance of internal waves in a stratified estuarine tidal flow. Ph.D. thesis, TU-Delft, The Netherlands (1995)

34. den Toonder, J.M.J.: Drag reduction by polymer additives in a turbulent pipe experiment. Ph.D. thesis, TU-Delft, The Netherlands (1996)

35. Draad, A.A.: Laminar-turbulent transition in pipe flow for Newtonian and non-Newtonian fluids. Ph.D. thesis, TU-Delft, The Netherlands (1996)

36. Dirkzwager, M.: A new axial cyclone design for fluid-fluid separation. Ph.D. thesis, TU-Delft, The Netherlands (1996)

37. Boersma, B.J.: Electromagnetic effects in cylindrical pipe flow. Ph.D. thesis, TU-Delft, The Netherlands (1997)

38. Meeder, J.P.: Numerical simulation of chemical reactions in point-source plumes. Ph.D. thesis, TU-Delft, The Netherlands (1998)

39. Versteegh, T.A.M.: Numerical simulation of natural convection in a differentially heated, vertical channel. Ph.D. thesis, TU-Delft, The Netherlands (1998)

40. van Dijk, A.: Aliasing in one-point turbulence measurements: theory, DNS and hotwire experiments. Ph.D. thesis, TU-Delft, The Netherlands (1999)

41. van Haarlem, B.A.: The dynamics of particles and droplets in atmospheric turbulence - a numerical study. Ph.D. thesis, TU-Delft, The Netherlands (2000)

42. van der Hoeven, J.G.Th.: Observations in the turbulent boundary-layer - high resolution DPIV measurements over smooth and riblet surfaces. Ph.D. thesis, TU-Delft, The Netherlands (2000)

43. Verhelst, J.: Model evaluation and dynamics of a visoelastic fluid in a complex flow. Ph.D. thesis, TU-Delft, The Netherlands (2001) 
44. Brethouwer, G.: Mixing of passive and reactive scalars in turbulent flows. A numerical study. Ph.D. thesis, TU-Delft, The Netherlands (2001)

45. Treurniet, T.C.: Direct numerical simulation of premixed turbulent combustion. Ph.D. thesis, TU-Delft, The Netherlands (2002)

46. Ptasinski, P.K.: Turbulent flow of polymer solutions near maximum drag reduction: experiments simulations and mechanisms. Ph.D. thesis, TU-Delft, The Netherlands (2002)

47. Aanen, L.: Measurement of turbulent scalar mixing by means of a combination of PIV and LIF. Ph.D. thesis, TU-Delft, The Netherlands (2002)

48. Vrieling, A.J.: Numerical simulations of competitive-consecutive reactions in turbulent channel flow. Ph.D. thesis, TU-Delft, The Netherlands (2003)

49. Gavarini, M.I.: Initial stage of transition and optimal control of streaks in Hagen-Poisseuille flow. Ph.D. thesis, TU-Delft, The Netherlands (2004)

50. Breugem, W.P.: The influence of wall permeability on laminar and turbulent flows - theory and simulations. Ph.D. thesis, TU-Delft, The Netherlands (2005)

51. Nieuwstadt, F.T.M.: Turbulentie, epsilon uitgaven. Utrecht, The Netherlands (1992)

52. Tennekes, H., Lumley, J.L.: A first course in turbulence. The MIT Press, USA (1972) 